\title{
Letter about outcome differences between recanalized malignant central airway obstruction from endoluminal disease versus extrinsic compression
}

\author{
Yahua $\mathrm{Li}^{1}$ • Jianzhuang Ren ${ }^{1}$ - Jianjian Chen ${ }^{1} \cdot$ Xinwei Han ${ }^{1}$ (B) \\ Received: 26 November 2018 / Accepted: 22 January 2019 / Published online: 28 February 2019 \\ (C) Springer-Verlag London Ltd., part of Springer Nature 2019
}

We read with great interest the article by Verma [1] and colleagues. They draw the conclusion that malignant central airway obstruction $(\mathrm{CAO})$ from endoluminal lesions recanalized using Nd:YAG laser carries a better prognosis than malignant CAO from extrinsic compression recanalized with a selfexpendable metallic stent (SEMS). Here, we have some opinions to share.

The author illustrated that reported median survival in advanced esophageal cancer with $\mathrm{CAO}$ is about 2.8 months, while adenoid cystic carcinoma, mucoepidermoid cancer, and carcinoid with longer life expectancy. A total of $10(33.3 \%)$ patients are esophageal cancer in the "stent only" group and no one in the "laser only" group $(p=0.0001)$. It is obvious that a bias exists.

Also, the author pointed out that patients with lobar bronchi stenosis had a better survival compared to those with trachea and bronchi involvement. However, there were $6(16.67 \%)$ patients with lung lobe stenosis in the "laser only" group and no one in the "stent only" group in this study. Although the number of stenosis cases in the trachea and bronchus are the same, the complex

Xinwei Han

hanxinwei2006@163.com

Yahua Li

liyahua1990@163.com

Jianzhuang Ren

rjzjrk@126.com

Jianjian Chen

chen_jianjian@foxmail.com

1 Department of Interventional Radiology, The First Affiliated Hospital of Zhengzhou University, Zhengzhou 450052, China (mixed) stenosis cases in the "stent only" group are 5 and only one in the "laser only" group. Usually, the results of complex stenosis cases are not as good as simple stenosis cases [2].

The most common complication about SEMS is granulation tissue hyperplasia, which would also cause endoluminal stenosis and seriously affect the ventilation of the airway. In this situation, other interventions are needed to deal with it. The treatment of "only stent" may not be a good choice, and it will affect the lifespan of patients with a tracheal stent.

Finally, the cause of patients' death in this study was not mentioned. CAO caused by esophageal cancer sometimes with accompanying fistula would bring infection and deteriorate the health condition of patients. This also brings the poor results of the "stent only" group.

Based on the data mentioned above, the outcome difference of this study needs further investigation.

Publisher's note Springer Nature remains neutral with regard to jurisdictional claims in published maps and institutional affiliations.

\section{References}

1. Verma A, Goh SK, Tai DYH et al (2018) Outcome differences between recanalized malignant central airway obstruction from endoluminal disease versus extrinsic compression [J]. Lasers Med Sci. https://doi.org/10.1007/s10103-018-2684-5

2. Dalar L, Karasulu L, Abul Y et al (2016) Bronchoscopic treatment in the management of benign tracheal stenosis: choices for simple and complex tracheal stenosis[J]. Ann Thorac Surg 101(4):1310-1317 